\title{
Optimal Guaranteed Service Time and Service Level Decision with Time and Service Level Sensitive Demand
}

\author{
Sangjun Park ${ }^{1}$ and Ki-sung Hong ${ }^{2}$ \\ ${ }^{1}$ Graduate School of Information Management and Security, Korea University, 145 Anam-ro, Seongbuk-gu, Seoul 136-701, \\ Republic of Korea \\ ${ }^{2}$ Graduate School of Management of Technology, Korea University, 145 Anam-ro, Seongbuk-gu, Seoul 136-701, Republic of Korea
}

Correspondence should be addressed to Ki-sung Hong; justlikewind@korea.ac.kr

Received 28 February 2014; Revised 31 May 2014; Accepted 2 June 2014; Published 22 June 2014

Academic Editor: Changzhi Wu

Copyright (C) 2014 S. Park and K.-s. Hong. This is an open access article distributed under the Creative Commons Attribution License, which permits unrestricted use, distribution, and reproduction in any medium, provided the original work is properly cited.

\begin{abstract}
We consider a two-stage supply chain with one supplier and one retailer. The retailer sells a product to customer and the supplier provides a product in a make-to-order mode. In this case, the supplier's decisions on service time and service level and the retailer's decision on retail price have effects on customer demand. We develop optimization models to determine the optimal retail price, the optimal guaranteed service time, the optimal service level, and the optimal capacity to maximize the expected profit of the whole supply chain. The results of numerical experiments show that it is more profitable to determine the optimal price, the optimal guaranteed service time, and the optimal service level simultaneously and the proposed model is more profitable in service level sensitive market.
\end{abstract}

\section{Introduction}

Increased competition has driven firms to introduce new products (or services) in the market, and service time (lead time) has evolved as the competitive paradigm $[1,2]$. As service time has become a key for business success, service time reduction has emerged as a key competitive edge [3-5]. The time-based competition became a new competitive paradigm.

In a time sensitive market, firms exploit customers' sensitivity to time to increase prices in return for a shorter service time. For instance, a logistics service provider charges more in transportation costs to an express delivery user compared to a regular delivery user. Likewise, firms differentiate their products based on service times in order to maximize the firm's revenue [6]. In this case, the service time reduction has provided firms with new opportunities. Additionally, in today's global economy, firms are increasingly depending on fast response times as an important source of sustainable competitive advantage. Considering the influence of service times on demand is therefore needed.
The potential for increased demand and price premium creates an incentive for firms to reduce the length of the service time. While this strategy may attract customers, there is a risk that demand may exceed the firms' capacity to respond. This can lead to a decrease in demand.

As shown in Figure 1, a customer's demand is affected by not only the price for the service and the guaranteed service time but also the service level (quality of service, QoS) that is defined as the minimum probability of meeting the guaranteed service time. Such tradeoffs must be considered when making decisions about a guaranteed service time strategy, and thus the integrated price, the guaranteed service time, and the service level decision are needed.

In this paper, we consider a two-stage supply chain with one supplier and one retailer. The retailer sells a product to customer and the supplier provides a product in a make-toorder mode. In this case, the supplier's decisions on service time and service level and the retailer's decision on retail price have effects on customer demand. The objective is to develop an optimization model to determine the optimal guaranteed service time, the optimal service level, and the 


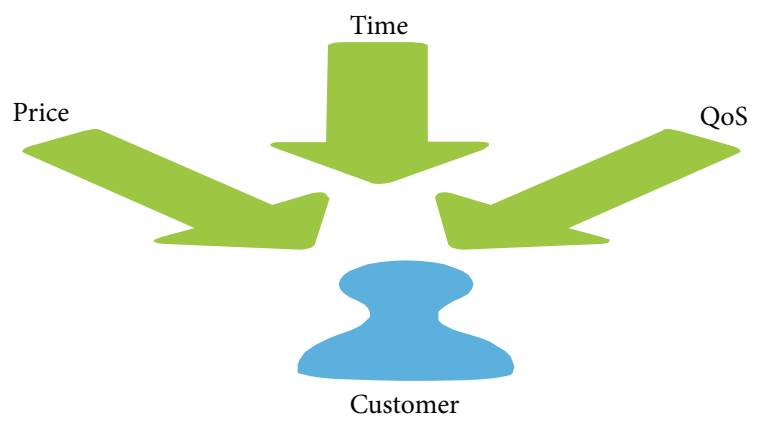

FIgURE 1: The influence of price, time, and QoS on customer demand.

optimal capacity to maximize the expected profit of the whole supply chain. The optimization model takes into account that reducing service time by increasing capacity will require investment, and the supplier must be able to satisfy the guaranteed service time according to the service level.

The rest of this paper is organized as follows. Section 2 provides a review of the literature on time-based competition. In Section 3, we formulate the mathematical models to determine the price, the guaranteed service time, the service level, and the capacity and optimal properties for the models are obtained in Section 4. To gain a further insight, in Section 5, we conduct computational experiments and analyze the sensitivity of the optimal decisions with respect to the model parameters. Our conclusions are provided in Section 6.

\section{Literature Review}

The pricing and service time decision was first studied by Stalk and Hout [7] who addressed the effect of time for strategic competitiveness. So and Song [8], Palaka et al. [9], Ray and Jewkes [10], and Hill and Khosla [11] also studied optimal pricing and service time decisions and modeled the service provider's operations as a single server queue. So and Song [8] studied the impact of using service time guarantees as a competitive strategy in service industries where demands are sensitive to both price and service time. They used an $\mathrm{M} / \mathrm{M} / 1$ queuing model and proposed a mathematical model to calculate the optimal price and service time. Palaka et al. [9] also used an M/M/1 queuing model and examined the lead-time setting, capacity utilization, and pricing decisions facing a firm serving customers sensitive to guaranteed lead times. They used numerical analysis to show that capacity utilization should be lower when customers are more sensitive to lead time. Ray and Jewkes [10] further extended Palaka et al's results [9] by explicitly modeling price as a function of delivery time and demand being a function of price and delivery time. Hill and Khosla [11] also studied a similar tradeoff between price and service time but in a deterministic framework.

So [12], Tsay and Agrawal [13], Allon and Federgruen [14], and Pekgun et al. [15] also studied similar problems but in a competitive setting where two firms selling a common product were competing on price and service time. So [12] used a multiplicative competitive interaction (MCI) model to represent the market shares of an arbitrary number of firms competing for the same product based on their prices and service time guarantees. Each firm was modeled as an $\mathrm{M} / \mathrm{M} / 1$ server, which aims to meet its promised delivery time guarantee with at least a certain degree of reliability. They showed how heterogeneous firms exploit their competitive advantage, in terms of a higher capacity or a lower operating cost, to differentiate their services. Pekgun et al. [15] studied two firms competing in a common market based on their price and lead-time decisions and explored the impact of centralization versus decentralization of these decisions, as quoted by the marketing and production departments, respectively. They modeled the competing firms as $\mathrm{M} / \mathrm{M} / 1$ servers and each firm's expected demand as a linear function of the prices and delivery times quoted by both firms. Allon and Federgruen [14] studied competition between an arbitrary number of firms. Each firm competed by advertising its price and expected waiting time and selected its optimal capacity level and a priority discipline to serve the customers. Tsay and Agrawal [13] studied a distribution system in a nonqueuing framework in which a manufacturer supplied a common product to two retailers who competed for end customers based on their retail prices and service. Xiao et al. [16] considered a supply chain consisting of one manufacturer that determines the wholesale price and lead time and one retailer that determines the retail price and developed an optimization model to determine the optimal wholesale price, the optimal guaranteed lead time, and the optimal retail price. Narenji et al. [17] studied the competition between two supply chains with demand sensitive to both price and delivery time and found the optimal policy of price and delivery time. However, these studies did not study service level decisions. This research, in contrast to the existing studies, focuses on the service time and the service level decision. We develop a mathematical model to determine the optimal guaranteed service time and the optimal service level to maximize the total profit.

Shang and Liu [18] investigated the behaviors of competing firms in industry where customers are sensitive to guaranteed delivery time and quality of service. However, they did not consider the price decision. Recently, Xiao and Qi [19] considered a two-stage supply chain with demand sensitive to price, delivery time, and delivery reliability standard and investigated the impact of the delivery reliability standard on the demand rate. They developed an optimization model to determine the optimal price, delivery time, and delivery reliability standard. However, they did not consider the capacity decision. In this study, we determine the optimal guaranteed service time, the optimal service level, and the optimal capacity simultaneously. 


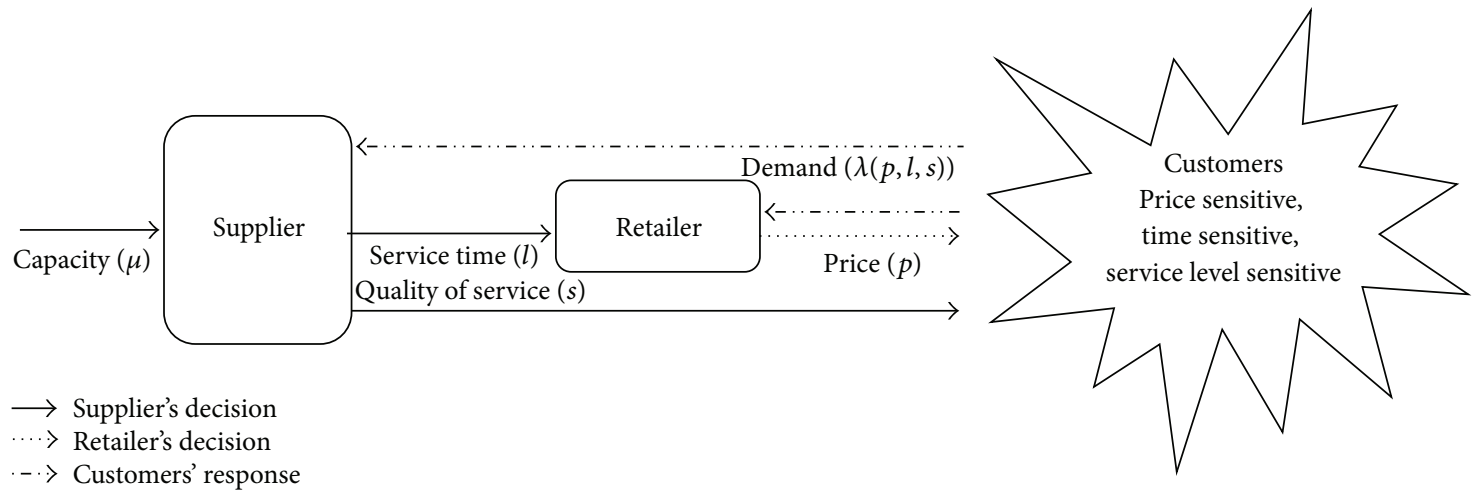

FIGURE 2: Schematic representation of a model.

\section{The Mathematical Model}

3.1. Demand Function. We consider a two-stage supply chain with one supplier and one retailer as shown in Figure 2. The retailer sells a product to customer at a retail price $(p)$ and the supplier provides a product in a make-to-order mode and announces a guaranteed service time $(l)$ and a service level $(s)$. Customer demands arrive according to a Poisson process with a mean rate $\lambda$. The service times of the demand are exponentially distributed with the mean rate $\mu$. Customers are served in a first-come-first-served fashion, and the arrival rate depends on the retail price, the service time, and the service level. We assumed that customers prefer shorter service time and lower prices and that the price is related to the length of the guaranteed service time. The service level $s(0<s<1)$ is the probability that a random customer will have an actual service time of $l$ or less. A failure to satisfy an arriving customer within the guaranteed service time $l$ might have an adverse impact on repeat business. That is, the lower service level decreases demand.

To further characterize the analytical model, we assume that the mean demand rate depends linearly on $p, l$, and $s$; that is,

$$
\lambda(p, l, s)=a-b p-c l+g s,
$$

where $a$ denotes the potential market size (a higher value of $a$ represents a higher overall potential for demand) and $b, c$, and $d$ represent the price, the service time, and the service level sensitivities of the mean demand rate, respectively $(a, b, c, g>$ $0)$. This demand function has been employed extensively in the literature relating to service time and service level decisions; see the studies by Shang and Liu [18], Xiao and Qi [19], Xu et al. [20], Xia and Yang [21], and Jamshidi and Fatemi Ghomi [22]. The linear demand function will help us obtain qualitative insights without much analytical complexity.

3.2. Supplier's Profit Function. The supplier can invest in increasing the service rate $\mu$ through, for example, acquiring improved equipment. In general, it is reasonable to assume that successive investments in increasing $\mu$ by the same amount will cost equal or more; that is, the investment cost function is increasing and linear in $\mu$. The supplier's cost structure includes two main categories: direct unit variable costs and investment costs. The direct unit variable costs mean all costs that are proportional to production volume, such as the cost of direct materials and labor. The investment costs mean the costs of increasing the capacity $\mu$. The direct unit variable cost and the investment cost for the service/product are denoted by $m$ and $A$, respectively. Finally, the objective is to maximize the supplier's profit per unit time, subject to satisfying the service reliability constraint.

We assume that the service provider's objective is to maximize the expected total profit, which can be expressed as

$$
\prod_{S}(l, s, \mu)=\left(w_{s}-m\right) \lambda(p, l, s)-A \mu
$$

where $w_{s}$ means the unit wholesale price of the supplier. In the expected profit function, $(w-m) \lambda(p, l, s)$ and $A \mu$ represent the expected net revenue and the investment cost, respectively. Thus, the mathematical model is expressed as follows:

$$
\begin{gathered}
\underset{l, s, \mu}{\operatorname{Maximize}}\left(w_{s}-m\right) \lambda(p, l, s)-A \mu, \\
\text { Subject to } \lambda(p, l, s) \leq \mu, \\
1-e^{-(\mu-\lambda) l} \geq s, \\
l>0, \quad \mu>0, \\
1>s \geq s_{c} .
\end{gathered}
$$

In this mathematical model, constraint (4) is system stability constraint that the supplier's mean service rate exceeds the mean demand rate. Constraint (5) represents that the actual service level is larger than the proposed service. Constraint (6) restricts the guaranteed service time and the capacity for the service/product to positive values. Constraint (7) represents that the proposed service level is greater than the industry standard service level $\left(s_{c}\right)$ and less than 1 . In this study, we assume that $s_{c}>0.5$.

3.3. Retailer's Profit Function. The retailer purchases a product from supplier at the wholesale price, $w_{s}$, and sells 
a product to customer at a retail price, $p$. We assume that the retailer's objective is to maximize the expected total profit, which can be expressed as

$$
\prod_{R}(p)=\left(p-w_{s}\right) \lambda(p, l, s)
$$

\section{The Optimal Decisions}

4.1. The Retailer's Optimal Decision on Retail Price. In this section, we derive the optimal property to calculate the optimal retail price. The optimal retail price to maximize the retailer's profit is obtained using the following proposition.

Proposition 1. The retailer's profit function (8) is the concave function of $p$. Thus, the optimal retail price, $p^{*}$, is obtained by taking the first-order derivative of the retailer's profit function, as given by (8):

$$
p^{*}=\frac{a-c l+g s+b w_{s}}{2 b} .
$$

Proof. Taking the first- and second-order derivatives of (8) with respect to $p$, we have

$$
\begin{gathered}
\frac{d \prod_{R}(p)}{d p}=a-c l+g s+b w_{s}-2 b p, \\
\frac{d^{2} \prod_{R}(p)}{d p^{2}}=-2 b<0,
\end{gathered}
$$

respectively. Since the second-order derivative is always less than zero, thus, the retailer's profit function (8) is concave with respect to $p$.

4.2. The Supplier's Optimal Decisions. In this section, we derive the optimal property to calculate the optimal service time, the optimal service level, and the optimal capacity. We first calculate the optimal capacity.

It is obvious that constraint (5) must be binding at optimality (see So and Song [8] and Palaka et al. [9]). Thus, the optimal capacity, $\mu^{*}$, is then

$$
\mu^{*}(l, s)=\frac{-\ln (1-s)}{l}+\lambda(l, s) .
$$

Substituting $\mu^{*}(l, s)$ in (2), the supplier's profit function can be expressed in terms of $l$ and $s$ :

$$
\prod_{S}(l, s)=\left(w_{S}-m-A\right) \lambda(p, l, s)+\frac{A \ln (1-s)}{l} .
$$

The optimal service time and service level to maximize the supplier's profit are obtained using the following proposition.
Proposition 2. The supplier's profit function (12) is jointly concave with respect to $l$ and $s$.

Proof. $H_{S 1}$ represents the Hessian matrix of the supplier's profit function (12) and is given by

$$
H_{S 1}=\left[\begin{array}{cc}
\frac{2 A \ln (1-s)}{l^{3}} & \frac{A}{l^{2}(1-s)} \\
\frac{A}{l^{2}(1-s)} & -\frac{A}{l(1-s)^{2}}
\end{array}\right] .
$$

The 1st leading principal minor is $(2 A \ln (1-s)) / l^{3}$ and is always less than zero for all $l$ and $s$. The 2 nd leading principal minor is $-\left(A^{2} / l^{4}(1-s)^{2}\right)[2 \ln (1-s)+1]$ and is always larger than zero for all $l$ and $s$. Thus, the Hessian is negative definite, so that the supplier's profit function is jointly concave with respect to $l$ and $s$.

4.3. Subgame Perfect Nash Equilibrium. We consider the following game: first, the supplier determines the service time and service level, and then the retailer determines the retail price. In this case, the retailer's best response on the supplier's decisions is $p^{*}(l, s)=\left(a-c l+g s+b w_{s}\right) / 2 b$. Thus, substituting $p^{*}(l, s)$ in (12), the supplier's profit function can be expressed in terms of $l$ and $s$ :

$$
\prod_{S}(l, s)=\left(w_{S}-m-A\right)\left(\frac{a-c l+g s-b w}{2}\right)+\frac{A \ln (1-s)}{l} .
$$

Theorem 3. The supplier's profit function (14) is jointly concave with respect to $l$ and $s$. Thus, there is a subgame perfect Nash equilibrium. The best response of the supplier solves the following:

$$
\begin{gathered}
-\frac{c}{2}(w-m-A)-\frac{A \ln (1-s)}{l^{2}}=0, \\
\frac{q}{2}(w-m-A)-\frac{A}{l(1-s)} .
\end{gathered}
$$

Proof. $H_{S 2}$ represents the Hessian matrix of the supplier's profit function (14) and is given by

$$
H_{S 2}=\left[\begin{array}{cc}
\frac{2 A \ln (1-s)}{l^{3}} & \frac{A}{l^{2}(1-s)} \\
\frac{A}{l^{2}(1-s)} & -\frac{A}{l(1-s)^{2}}
\end{array}\right] .
$$

The 1st leading principal minor is $(2 A \ln (1-s)) / l^{3}$ and is always less than zero for all $l$ and $s$. The 2 nd leading principal minor is $-\left(A^{2} / l^{4}(1-s)^{2}\right)[2 \ln (1-s)+1]$ and is always larger 
TABLE 1: Parameter values for the comparison.

\begin{tabular}{lc}
\hline Parameters & Values \\
\hline$m$ & {$[1,10]$} \\
$A$ & {$[1,10]$} \\
$a$ & {$[21,45]$} \\
$b$ & {$[0.1,2.5]$} \\
$c$ & {$[0.1,2.5]$} \\
$g$ & {$[2,50]$} \\
\hline
\end{tabular}

than zero for all $l$ and $s$. Thus, the Hessian is negative definite, so that the supplier's profit function is jointly concave with respect to $l$ and $s$. Therefore, the optimal service time and optimal service level are obtained by taking the first-order derivative of the supplier's profit function with respect to $l$ and $s$, respectively.

\section{Numerical Experiments}

5.1. Performance of the Proposed Model. To determine whether the service level decision is efficient in terms of the total profit, we compare the performance (total profit) of the two models (the proposed model and the existing model that assumes that the service level is given, such as Ray and Jewkes' [10] model). For this comparison, we will use the data from the study by Xiao and Qi [19], as shown in Table 1.

The performance of each model is represented by the percentage increase in profit, $\Delta p \%$, that is computed by

$$
\begin{aligned}
\Delta p \% & \\
= & \frac{\text { Profit of proposed model }- \text { Profit of existing model }}{\text { Profit of existing model }} \\
& * 100 \% .
\end{aligned}
$$

The particular scenario satisfying $m=5, A=10, a=40$, $b=1, c=1$, and $g=50$ is shown in Table 2, and we observe that the profit of the proposed model is always higher than that of Ray and Jewkes' [10] model. This trend is observed for all combinations of $m, A, a, b, c$, and $g$. Thus, on the basis of these experiments, we conclude that it is more profitable to determine the optimal price, the optimal guaranteed service time, and the optimal service level simultaneously.

As shown in Figure 3, the average $\Delta p \%$ increases as the service level sensitivity increases. This trend is observed for all combinations of $m, A, a, b, c$, and $g$. Thus, on the basis of these experiments, we conclude that the proposed model is more profitable in service level sensitive market.

5.2. Sensitivity Analysis. In this section, we examine the effects of the parameters on the optimal decisions and analyze

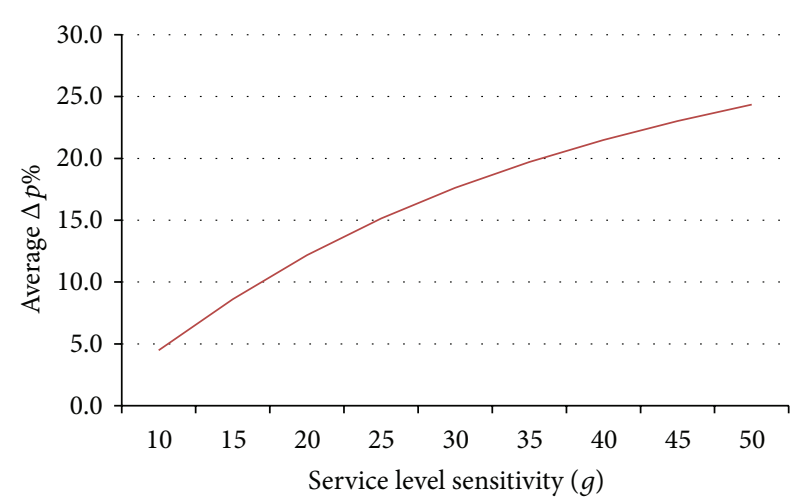

Figure 3: Average $\Delta p \%$ versus service level sensitivity.

the sensitivity of the optimal price, the optimal service time, and the optimal service level with respect to the parameters $m, A, a, b, c$, and $g$. Since the analysis is not tractable, we perform numerical experiments and identify the impact through graphical means. For this comparison, we will use the same data in Table 1.

Table 3 shows how changes in the parameters affect the optimal decisions. One feature of Table 3 is that the supplier behaves in a somewhat contradictory way by increasing their service time and decreasing their service level as the cost parameters ( $m$ and $A$ ) increase. The high values of $m$ and $A$ will lead to less investment in capacity. Thus, supplier increases the service time and decreases the service level. As shown in Table 3, the service time and the service level decrease as the service time sensitivity $(c)$ increases. When $c$ increases, in order to attract many customers, the supplier offers a short service time to customer and decreases the service level to satisfy the short service time. Also, we observe that the service time and the service level increase as the service level sensitivity $(g)$ increases. The high value of $g$ will lead to the high service level. Thus, the supplier increases their service time to satisfy the high service level.

\section{Conclusions}

In this study, we considered a two-stage supply chain with one supplier and one retailer. We assumed that the supplier's decisions on service time and service level and the retailer's decision on retail price have effects on customer demand and developed optimization models to determine the optimal retail price, the optimal guaranteed service time, the optimal service level, and the optimal capacity to maximize the expected profit of the whole supply chain. The results of numerical experiments showed that expected profit significantly increases using the proposed optimization model compared to the existing model that assumes that the service level is given. From the numerical results, we also observed that the proposed model is more profitable in service level sensitive market. 
TABLE 2: Comparison of the profits.

\begin{tabular}{|c|c|c|c|c|c|}
\hline \multicolumn{6}{|c|}{ Proposed model } \\
\hline$l^{*}$ & & & \multicolumn{2}{|c|}{$p^{*}$} & Total profit \\
\hline 2.931 & \multicolumn{2}{|c|}{0.986} & \multicolumn{2}{|c|}{55.693} & 292.28 \\
\hline \multicolumn{6}{|c|}{ Ray and Jewkes' [10] model } \\
\hline$s$ & $l^{*}$ & $p^{*}$ & Total profit & Profit gap & $\Delta p \%$ \\
\hline 0.50 & 1.177 & 44.411 & 188.2259 & 104.0563 & $55.3 \%$ \\
\hline 0.55 & 1.264 & 45.618 & 199.8627 & 92.41946 & $46.2 \%$ \\
\hline 0.60 & 1.354 & 46.823 & 211.4627 & 80.81944 & $38.2 \%$ \\
\hline 0.65 & 1.449 & 48.025 & 223.0099 & 69.27231 & $31.1 \%$ \\
\hline 0.70 & 1.552 & 49.224 & 234.4824 & 57.79971 & $24.6 \%$ \\
\hline 0.75 & 1.665 & 50.417 & 245.8489 & 46.43325 & $18.9 \%$ \\
\hline 0.80 & 1.794 & 51.603 & 257.0588 & 35.22338 & $13.7 \%$ \\
\hline 0.85 & 1.948 & 52.776 & 268.0212 & 24.26097 & $9.1 \%$ \\
\hline 0.90 & 2.146 & 53.927 & 278.5403 & 13.74182 & $4.9 \%$ \\
\hline \multirow[t]{2}{*}{0.95} & 2.448 & 55.026 & 288.0225 & 4.259625 & $1.5 \%$ \\
\hline & & \multicolumn{3}{|c|}{ Average $\Delta p \%$} & $24.4 \%$ \\
\hline
\end{tabular}

TABLE 3: Parameter values for the comparison.

\begin{tabular}{|c|c|c|c|c|c|c|}
\hline & $p^{*}$ & $l^{*}$ & $s^{*}$ & $\mu^{*}$ & $\lambda$ & Profit \\
\hline$m$ & Decreases & Increases & Decreases & Decreases & Decreases & Decreases \\
\hline$A$ & Decreases & Increases & Decreases & Decreases & Decreases & Decreases \\
\hline$a$ & Increases & No impact & No impact & Increases & Increases & Increases \\
\hline$b$ & Decreases & No impact & No impact & Decreases & Decreases & Decreases \\
\hline$c$ & Decreases & Decreases & Decreases & Decreases & Decreases & Decreases \\
\hline$g$ & Increases & Increases & Increases & Increases & Increases & Increases \\
\hline
\end{tabular}

\section{Conflict of Interests}

The authors declare that there is no conflict of interests regarding the publication of this paper.

\section{Acknowledgments}

This research was supported by Basic Science Research Program through the National Research Foundation of Korea (NRF) funded by the Ministry of Education (NRF2013R1A1A2064569). This research was also supported by a Korea University Grant.

\section{References}

[1] J. D. Blackburn, Time-Based Competition: The Next Battleground in American Manufacturing, Business One Irwin, Homewood, Ill, USA, 1991.

[2] S.-H. Hum and H.-H. Sim, "Time-based competition: literature review and implications for modelling," International Journal of Operations and Production Management, vol. 16, no. 1, pp. 7590, 1996.

[3] W. J. Hopp and M. L. Spearman, Factory Physics, McGraw-Hill Higher Education, New York, NY, USA, 2nd edition, 2000.

[4] R. Suri, Quick Response Manufacturing: A Companywide Approach to Reducing Lead Times, Productivity Press, New York, NY, USA, 1998.
[5] P. van Beek and C. van Putten, "OR contributions to flexibility improvement in production/inventory systems," European Journal of Operational Research, vol. 31, no. 1, pp. 52-60, 1987.

[6] T. Boyaci and S. Ray, "Product differentiation and capacity cost interaction in time and price sensitive markets," Manufacturing and Service Operations Management, vol. 5, no. 1, pp. 18-36, 2003.

[7] G. Stalk and T. M. Hout, Competing against Time, The Free Press, New York, NY, USA, 1990.

[8] K. C. So and J.-S. Song, "Price, delivery time guarantees and capacity selection," European Journal of Operational Research, vol. 111, no. 1, pp. 28-49, 1998.

[9] K. Palaka, S. Erlebacher, and D. H. Kropp, "Lead-time setting, capacity utilization, and pricing decisions lead-time dependent demand," IIE Transactions, vol. 30, no. 2, pp. 151-163, 1998.

[10] S. Ray and E. M. Jewkes, "Customer lead time management when both demand and price are lead time sensitive," European Journal of Operational Research, vol. 153, no. 3, pp. 769-781, 2003.

[11] A. V. Hill and I. S. Khosla, "Models for optimal lead time reduction," Production and Operations Management, vol. 1, no. 2, pp. 185-197, 1992.

[12] K. C. So, "Price and time competition for service delivery", Manufacturing and Service Operations Management, vol. 2, no. 4, pp. 392-409, 2000. 
[13] A. A. Tsay and N. Agrawal, "Channel dynamics under price and service competition," Manufacturing and Service Operations Management, vol. 2, no. 4, pp. 372-391, 2000.

[14] G. Allon and A. Federgruen, "Competition in service industries with segmented markets," Working Paper, Graduate School of Business, Columbia University, New York, NY, USA, 2008.

[15] P. Pekgun, P. M. Griffin, and P. Keskinocak, "Centralized vs. decentralized competition for price and lead-time sensitive demand," Working Paper, School of Systems and Industrial Engineering, Georgia Institute of Technology, Atlanta, Ga, USA, 2006.

[16] T. Xiao, D. Yang, and H. Shen, "Coordinating a supply chain with a quality assurance policy via a revenue-sharing contract," International Journal of Production Research, vol. 49, no. 1, pp. 99-120, 2011.

[17] N. Narenji, M. Fathian, E. Telmoury, and S. G. J. Naini, "Price and delivery time analyzing in competition between an electronic and a traditional supply chain," Mathematical Problems in Engineering, vol. 2013, Article ID 596897, 12 pages, 2013.

[18] W. Shang and L. Liu, "Promised delivery time and capacity games in time-based competition," Management Science, vol. 57, no. 3, pp. 599-610, 2011.

[19] T. Xiao and X. Qi, "A two-stage supply chain with demand sensitive to price, delivery time, and reliability of delivery," Annals of Operations Research, 2012.

[20] Q. Xu, Z. Liu, and B. Shen, "The impact of price comparison service on pricing strategy in a dual-channel supply chain," Mathematical Problems in Engineering, vol. 2013, Article ID 613528, 13 pages, 2013.

[21] T. Xiao and D. Yang, "Price and service competition of supply chains with risk-averse retailers under demand uncertainty," International Journal of Production Economics, vol. 114, no. 1, pp. 187-200, 2008.

[22] R. Jamshidi and S. M. T. Fatemi Ghomi, "Service impact on customer demand and member profit in a supply chain," in Proceedings of the IEEE International Conference on Industrial Engineering and Engineering Management (IEEM '11), pp. 923927, December 2011. 


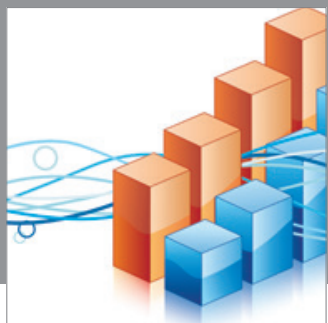

Advances in

Operations Research

mansans

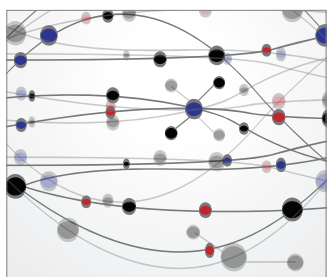

The Scientific World Journal
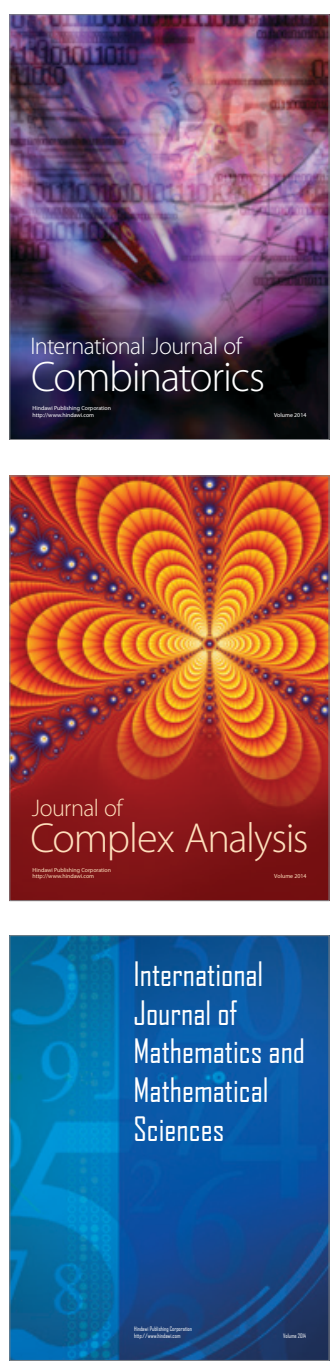
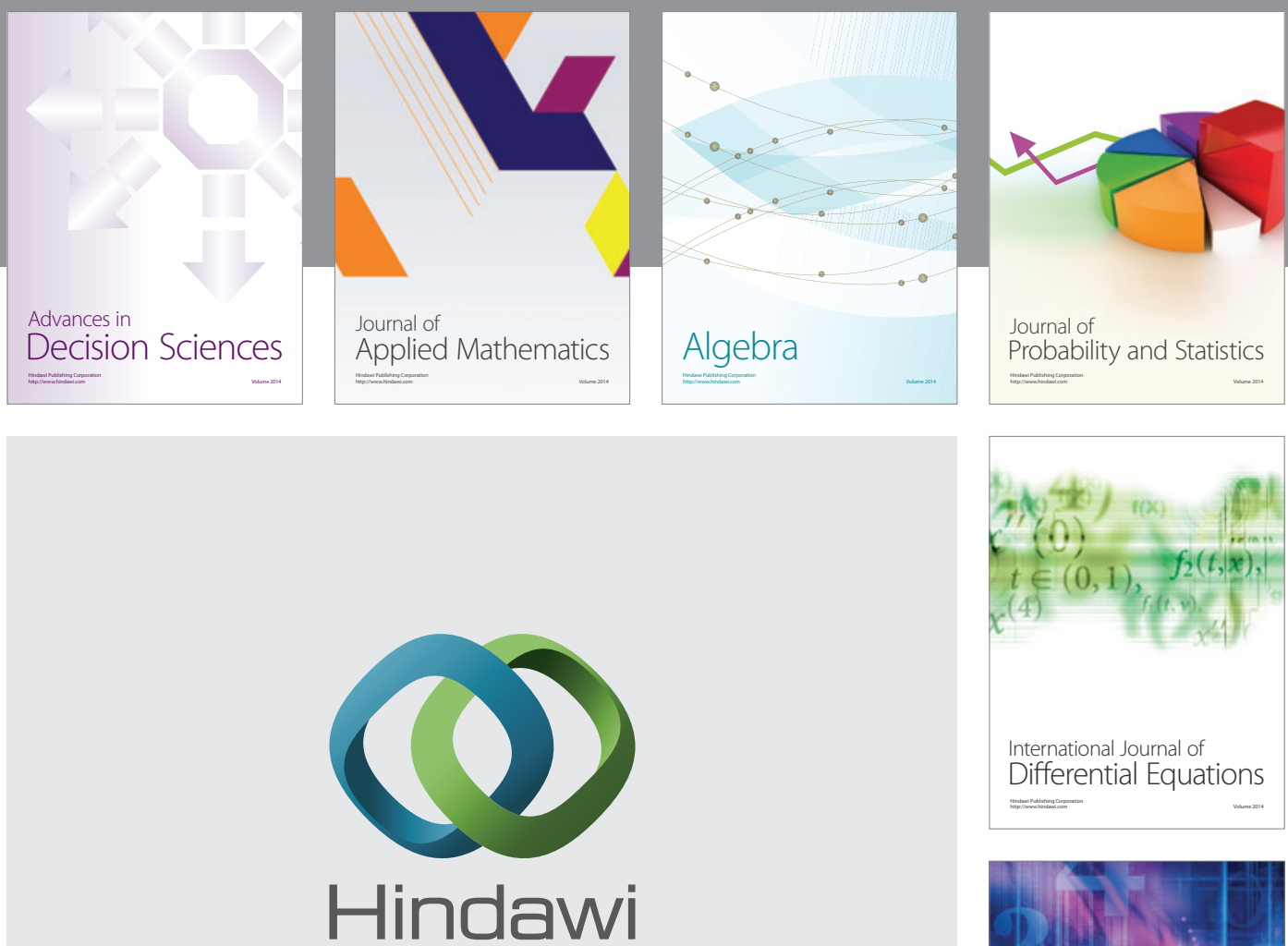

Submit your manuscripts at http://www.hindawi.com
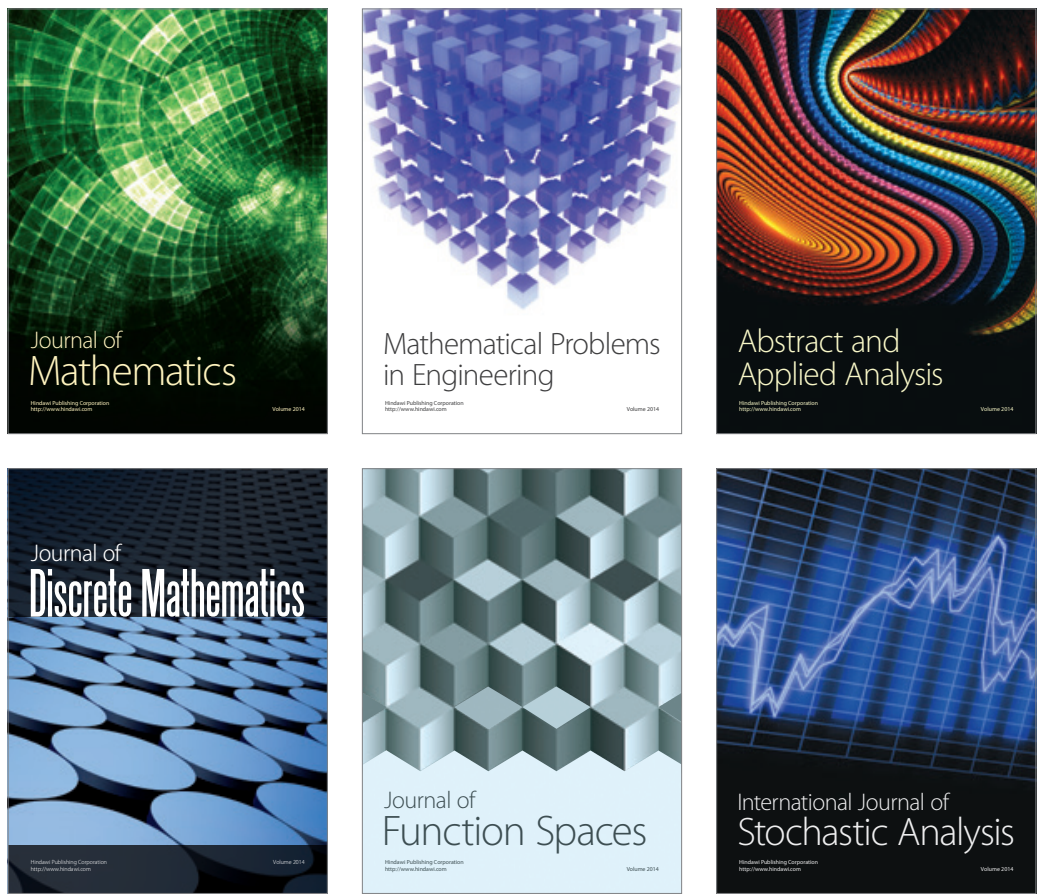

Journal of

Function Spaces

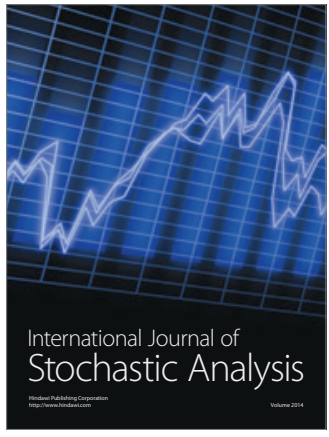

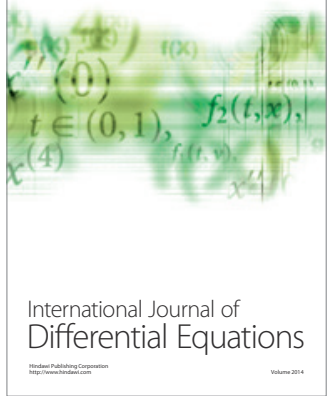
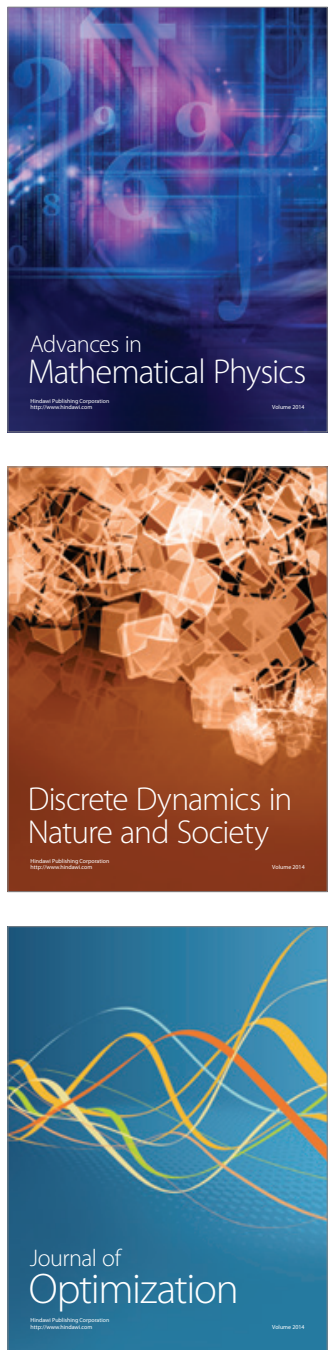